\title{
CONSTRUINDO UMA OFICINA VIRTUAL DE VÍDEO E VIDEOCONFERENCIA INTERATIVA
}

\author{
Mára Lúcia Fernandes Carneiro \\ mara.carneiro@ufrgs.br \\ UFRGS - Instituto de Psicologia - Depto. de Psicologia Social e institucional \\ Paulo Cabral \\ pazcabral@yahoo.com.br \\ Carlos Eduardo Caldas \\ caducaldas@ufrgs.br \\ Fernanda Bulla \\ fernandabulla@gmail.com \\ UFRGS/TV - Faculdade de Biblioteconomia e Comunicação
}

RESUMO: O texto apresenta relato de um projeto em andamento que visa à implementação de uma oficina virtual de vídeo e videoconferência, com vistas a apoiar a formação de docentes, alunos e demais interessados no uso deste recurso na educação a distância. O texto descreve como a equipe envolvida buscou aliar os conhecimentos da área da comunicação na produção de vídeos para construir uma experiência de navegação desafiadora para os usuários.

Palavras chave: videoconferência, objeto de aprendizagem, oficina virtual

ABSTRACT: This paper presents a description of an ongoing project that deals about videoconference as a virtual workshop. Its objective is to support the teachers, students and other users who want to use videoconference as a resource and support to distance education. This paper describes how the group of investigators tries to combine the expertise in video production to build a challenging experience of navigation.

Keywords: videoconference, learning objects, virtual workshop

\section{INTRODUÇÃO}

A videoconferência, com o avanço tecnológico e a ampliação das velocidades de conexão à Internet, deixou de ser aquele recurso inicialmente previsto para apoiar reuniões de executivos, distribuídos em filiais de uma empresa ao redor do mundo, para participar de nosso dia a dia de sala de aula.

A videoconferência é atualmente um recurso hoje muito utilizado também pelos professores como apoio as suas aulas em curso a distância. No entanto, um estudo e análise de algumas conferências, relatos de experiências e dicas para participar de uma videoconferência (CRUZ e BARCIA, 2003; MONTES e MOLINA, 2001; TAROUCO et alii, 2003) bem como os inúmeros tutoriais disponíveis (Texas State, Guelph, British Columbia, etc.) indicam que a falta de sucesso no uso deste recurso pode ser devido ao desconhecimento de suas potencialidades.

O caminho encontrado para compartilhar estas orientações foi a implementação de um objeto de aprendizagem que reunisse e disponibilizasse essas orientações, através do que denominou-se "Oficina virtual de vídeo e videoconferência".

Esta implementação foi dividida em três abordagens, envolvendo os temas: 


\section{Como participar de uma videoconferência}

O objeto propõe-se a apresentar orientações gerais sobre postura, vestuário, iluminação, uso do microfone, etc. na forma de animações interativas, de forma que o usuário possa experimentar várias possibilidades e intuitivamente distinguir quais as orientações adequadas.

\section{Construindo um vídeo}

Gravações de demonstrações dos diversos recursos e orientações para que ocorra uma boa videoconferência ou gravação de vídeo e orientações gerais para a construção de um roteiro de gravação.

\section{Como criar apresentações}

A preparação de apresentações (slides) é um recurso cada vez mais usual na comunidade acadêmica. No entanto, as possibilidades que os programas de edição apresentam nem sempre são utilizadas plenamente, quer por desconhecimento dos recursos técnicos, quer por desconhecimento de aspectos estéticos. O objeto propõe-se a apresentar orientações técnicas e estéticas que favorecerão a construção de slides que explorem estes aspectos de modo mais intenso, além de sua interação com vídeos e videoconferências.

Apoiado por edital SEAD/UFRGS, o projeto em andamento conta com três bolsistas, sob a supervisão e orientação de três docentes. A seguir, descrevemos as atividades já realizadas e aquelas ainda em andamento.

\section{VIDEOCONFERENCIA E O USO PELOS PROFESSORES}

Como destaca Cruz (1999a), após muitos séculos sem alterações no cenário educacional, os avanços na telemática permitiram que a escola ultrapassasse seus limites físicos, podendo se constituir como um grande espaço virtual. Este novo espaço de aprendizagem pode ser composto por diversos locais geográficos, situados a distâncias variadas, interligados por sistemas de comunicação que permitem o contato audiovisual entre professores e seus alunos e agregam diversos recursos tecnológicos. Toda esta tecnologia está provocando uma modificação na dinâmica da sala de aula.

Em suas pesquisas, Cruz (1999a, 1999b) descreve algumas experiências realizadas no Programa de Pós-Graduação em Engenharia de Produção da Universidade Federal de Santa Catarina (PPGEP-UFSC). A primeira tentativa dos professores é de reproduzir os procedimentos e recursos utilizados na sala de aula tradicional, não considerando as possibilidades de interação que um ambiente rico em tecnologia e a conexão por videoconferência entre diversas salas remotas podem proporcionar.

As experiências envolveram tanto salas conectadas ponto-a-ponto como conferências multiponto. Neste segundo caso, a imagem que aparece para todos é daquela sala onde o áudio predomina, enquanto que a sala que está enviando este áudio assiste À imagem da sala que falou por último. Dulce Cruz também destaca que é

inegável que essa cultura audiovisual modifica a percepção que se tem da aula e de como deve ser o comportamento tanto do professor quanto do aluno (CRUZ, 1999a, p.7).

Muitos problemas podem surgir da cultura de "assistir televisão", que associa o fato do uso de vídeo com uma baixa expectativa pelos conteúdos proporcionados e alta expectativa em relação aos recursos e efeitos especiais utilizados na produção, além de uma postura passiva da audiência.

Uma das estratégias sugeridas é proporcionar a familiarização dos alunos com a tecnologia envolvida, incluindo ao máximo uma variedade de recursos para apoio à 
interação, desde conversas telefônicas, correio eletrônico, vídeo e conferências (WILLIS, 1992 apud CRUZ, 1999a, p. 9).

Por outro lado, é fundamental considerar a preparação dos professores, não só familiarizando-os no uso dos equipamentos, mas propiciando espaços de experimentação. Orientações sobre comportar-se perante a câmera e sobre o uso do microfone podem e devem ir além da simples apresentação ao recurso. Desta forma, é possível também prepará-los para que possam criar um "ambiente criativo, cooperativo, utilizando ao máximo as qualidades (ou defeitos) que a tecnologia oferece" (CRUZ, 1999a, p. 9).

Este fator é importante, pois o professor defronta-se com uma situação bastante diferenciada da sala de aula presencial a qual está acostumado. Se ele não estiver preparado para enfrentar a sensação de estranhamento e desconforto, há grande risco da aula tornar-se um espaço para a simples transmissão de conhecimento, onde o professor fala, mas não dá voz aos seus alunos.

Outra percepção do professor pode ser a de que há um afastamento de seus alunos, causado pela interface tecnológica. Cruz sugere que o equipamento se torne parte integrante da aula ("transparente") e que se crie um clima de solidariedade entre professor e alunos, democratizando seu controle. E a tecnologia passa a fazer parte da ação do professor na medida em que ele se familiariza e se sente à vontade para utilizála de forma integrada a sua proposta pedagógica (CARNEIRO, 2003).

\section{A EXPERIÊNCIA PILOTO}

Para que a equipe conhecesse melhor o sistema de videoconferência e as necessidades de produção de vídeo para implementar uma oficina virtual, foi realizada uma experiência piloto. Nessa experiência, foram simuladas e filmadas várias situações que normalmente ocorrem em encontros via videoconferência, como, por exemplo, interferência no áudio, iluminação inadequada, falta de enquadramento, problemas com a postura do professor, entre outros. As imagens da Figura 1 exemplificam algumas dessas situações.

A partir dessa gravação e da posterior análise, foi possível verificar que alguns aspectos poderiam ser melhorados, para que os vídeos pudessem atender às características esperadas para um objeto de aprendizagem.

Um dos primeiros aspectos identificados foi o tempo de duração dos vídeos a serem disponibilizados na oficina virtual, pois a duração excessiva poderia cansar o usuário e dispersar o foco. Por isso, a partir de alguns testes, foi decidido que os vídeos teriam duração aproximada de dois minutos. Dessa forma, o expectador teria um tempo mínimo para assimilar as informações, sem ficar cansado na frente do monitor. Também foi levado em consideração o fato de que, quando o vídeo é muito extenso, raramente as pessoas apresentam interesse em assistir a filmagem por inteiro.

Outro aspecto relevante observado foi quanto à necessidade da criação de roteiros, para ter melhor controle sobre as gravações. Além disso, o roteiro auxiliaria na continuidade das cenas e no estabelecimento do tempo.

Então, decidiu-se criar um roteiro para cada problema encontrado na execução de uma videoconferência. Os assuntos escolhidos inicialmente foram: áudio, iluminação, planos/enquadramentos, postura e vestuário. 


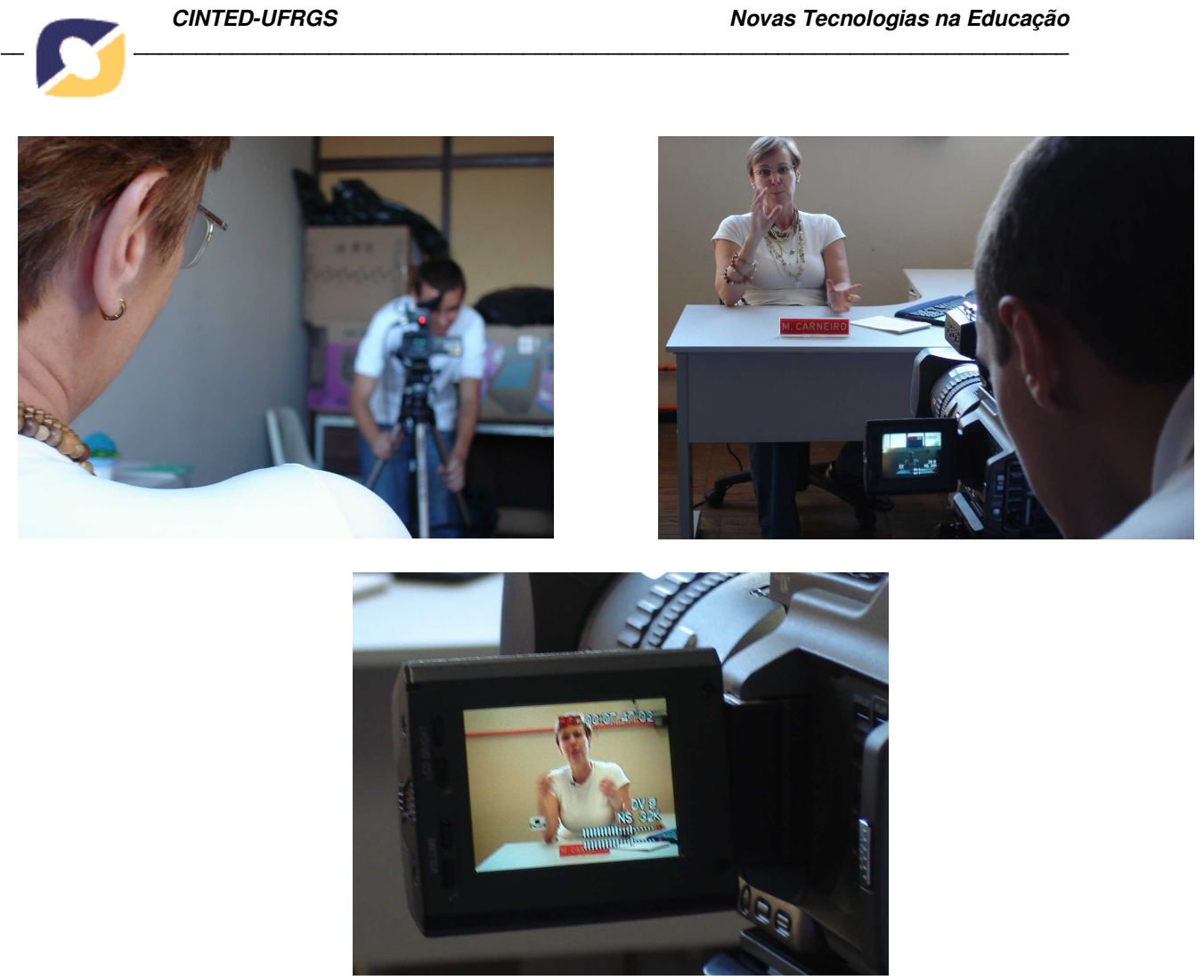

\section{Elaboração do roteiro}

Figura 1- Cenas das gravações da experiência piloto

Para Field, o roteiro "é uma história contada em imagens, diálogos e descrições, localizada no contexto da estrutura dramática" (2001, p.2). Foi com essa concepção que a equipe iniciou a elaboração dos roteiros, buscando uma descrição bastante específica para cada cena, o que facilitaria a pré-produção (preparação do local, participantes, equipamentos, etc.) e filmagem.

Essa elaboração prévia é muito importante, pois é uma forma de organizar as idéias (não correndo o risco de esquecê-las). E, como afirma Orson Welles, "pode-se fazer um mau filme de um bom roteiro, mas jamais alguém fará um bom filme de um roteiro ruim".

Roteirizar as idéias envolveu não só os conhecimentos sobre técnicas de comunicação, mas também o entendimento da mídia em que equipe iria trabalhar. Da área da comunicação, sabia-se que o vídeo carecia de uma linguagem própria, curta duração (para não ser cansativo) e textos elaborados para os ouvidos (já que provavelmente seria ouvido apenas uma vez pelo telespectador). Procurou-se elaborar então um roteiro com informações simplificadas e com uma linguagem coloquial, seguindo as orientações de Saboya, que afirma

A diferença básica entre um texto de livro e o de TV é que um foi feito para os olhos e o outro para os ouvidos [...] Por isso, lembre bem que as frases devem ser curtas, concisas, fortes, objetivas, na forma coloquial, e não devem deixar dúvidas para quem vê e ouve a interpretação da ação."(SABOYA, 1992, p.49)

Outro aspecto relevante era o som, pois este é um elemento de suporte às imagens. Havia a preocupação em elaborar um vídeo onde o som fosse usado de forma a reforçar, fortalecer o impacto da mensagem. 
Primeiramente elaborou-se um roteiro literário, onde as idéias foram reunidas em formato de texto normal, como se a equipe estivesse escrevendo uma história. Em seqüência foi elaborado o roteiro mais importante, próprio para as filmagens, chamado roteiro técnico. Seu diferencial concentra-se na sua maneira de formatação (que compreende a diagramação, o conteúdo e às técnicas de redação) com o propósito de atender as necessidades do veículo que seria utilizado. Esse roteiro consiste basicamente em descrever no lado esquerdo de uma folha todas as imagens e esquetes necessários em ordem. No lado direito ficam os áudios (gravações em off, trilhas, músicas,...) referentes às imagens que seriam utilizadas.

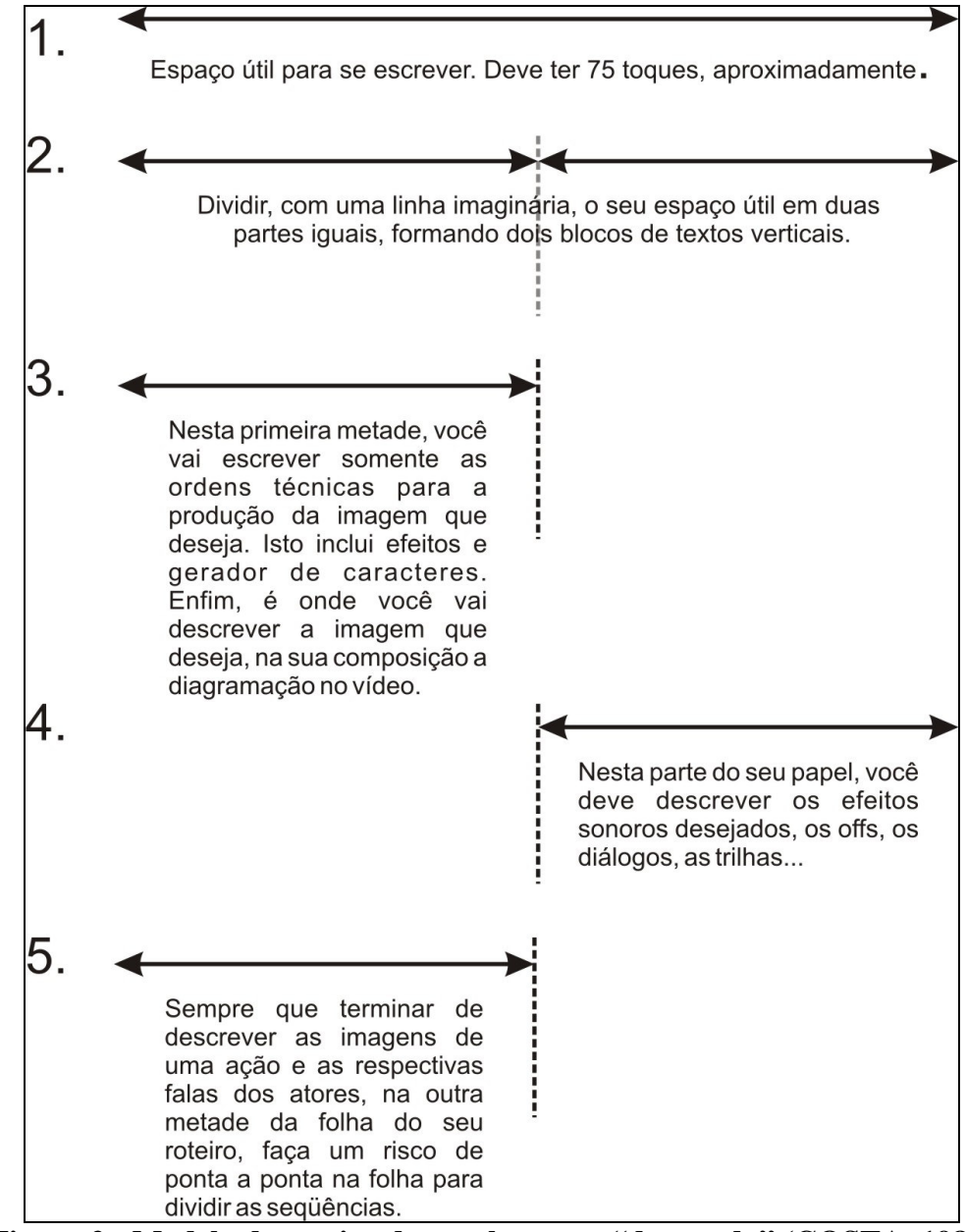

Figura 2 - Modelo de roteiro duas colunas ou "decupado”(COSTA, 1989)

Um modelo de roteiro (COSTA, 1989), é mostrado na Figura 2. Com esse tipo de roteiro consegue-se fazer uma estimativa da duração de cada seqüência do vídeo. A revisão do roteiro foi um momento bem importante, pois a leitura e revisão permitiram a identificação de alguns pontos que estavam mal esclarecidos e que precisavam de um maior detalhamento para ser entendidos pelo expectador.

\section{As gravações}

Para gerar novos vídeos que comporão oficina virtual, realizaram-se novas filmagens, agora em uma sala especial para videoconferências. Com uma câmera filmadora, foram gravadas cenas de uma professora que simulava alguns procedimentos 
inadequados para uma aula via videoconferência, como, por exemplo, utilizar roupas muito chamativas, reproduzindo e reformulando a experiência piloto.

Para que a edição permitisse a seleção de cenas, as gravações previram a filmagem de pelo menos $10 \%$ a mais de cenas do que as necessárias para a duração prevista para os vídeos.

Quando você está trabalhando com a câmera, filme e grave para editar. Faça suas tomadas de modo que suas opções de edição fiquem em aberto. Isso não significa que você deve registrar tudo que se move de todos os ângulos possíveis: isso seria tanto um desperdício quanto motivo de confusão. Significa, sim, que você deve planejar e filmar/gravar de modo a oferecer a mais ampla variedade de opções de corte possível. Essa é a idéia que sustenta a maioria dos tópicos desta seção". (WATTS, 199, p.30).

O apoio de um roteiro elaborado cuidadosamente e a pré-produção, que envolveu a seleção de figurinos, acessórios e recursos, foram essenciais para o êxito das gravações.

\section{Organização e estrutura dos vídeos}

Um cuidado na preparação da oficina virtual foi planejar uma estrutura de edição para que o vídeo fosse de fácil compreensão, porém não muito longo e cansativo. Assim, ficou decidido que a melhor maneira seria dividir o filme por módulos de assunto, permitindo que o usuário possa assistir ao vídeo sobre o tema que mais lhe interessar ou na sequiência que julgar mais conveniente para sanar suas dúvidas. Por exemplo, o módulo "áudio" conterá todos os problemas encontrados em uma videoconferência, relacionados aos equipamentos de som (microfone, alto-falante, fone de ouvido, etc.); no módulo "postura", os problemas relacionados com a forma de agir do professor e assim sucessivamente.

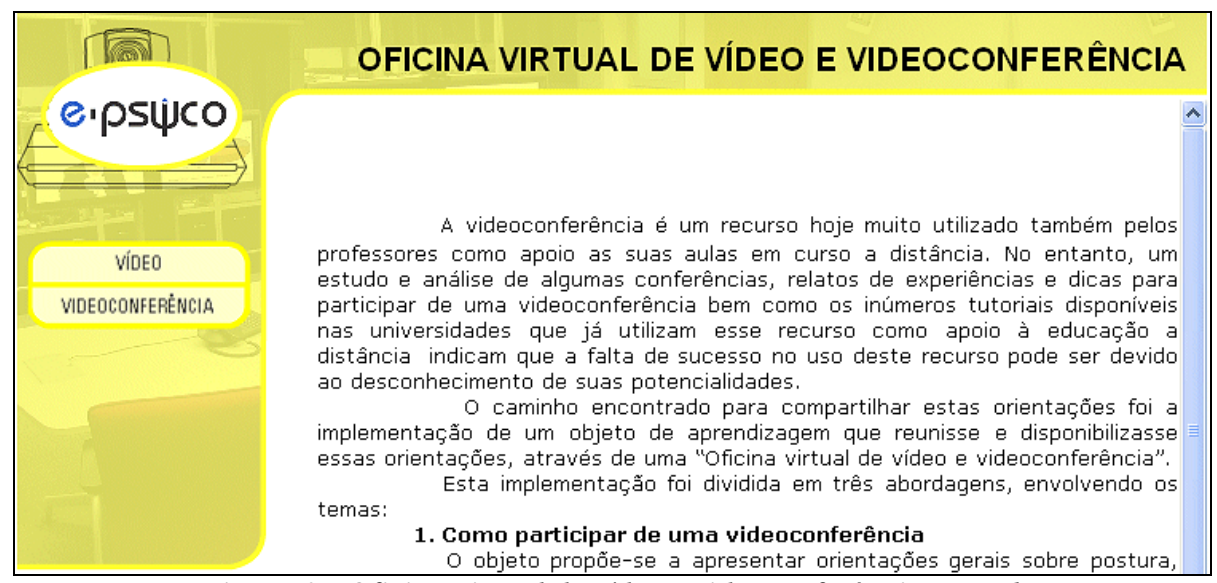

Figura 3 - Oficina virtual de vídeo e videoconferência na web

Outro aspecto que foi analisado e considerado interessante seria a elaboração de esquetes. Segundo o dicionário Houaiss (2001), "esquetes são pequenas cenas cômicas, sem necessariamente possuírem ligações entre si". Ou seja, o roteiro previu a realização de pequenas encenações, exemplificando os problemas encontrados nessa situação de educação a distância para facilitar a visualização e o entendimento do telespectador. As soluções desses problemas serão então apresentadas em formato de dicas, com orientações mais técnicas e específicas sobre cada tema. 
Outra preocupação tem sido em relação à maneira com que o vídeo seria apresentado e acessado pelos usuários da oficina virtual, optando-se pela implementação de acesso via web, através de um hipertexto (Figura 3).

Ao acessar o menu "Videoconferência", o usuário visualizará uma réplica de uma sala de videoconferência, com os elementos básicos envolvidos (a televisão para recepção da imagem remota, a câmera, a iluminação, o microfone, a câmera de documentos, etc.). A Figura 4 mostra uma primeira versão da imagem que servirá de base para a animação prevista no objeto de aprendizagem.

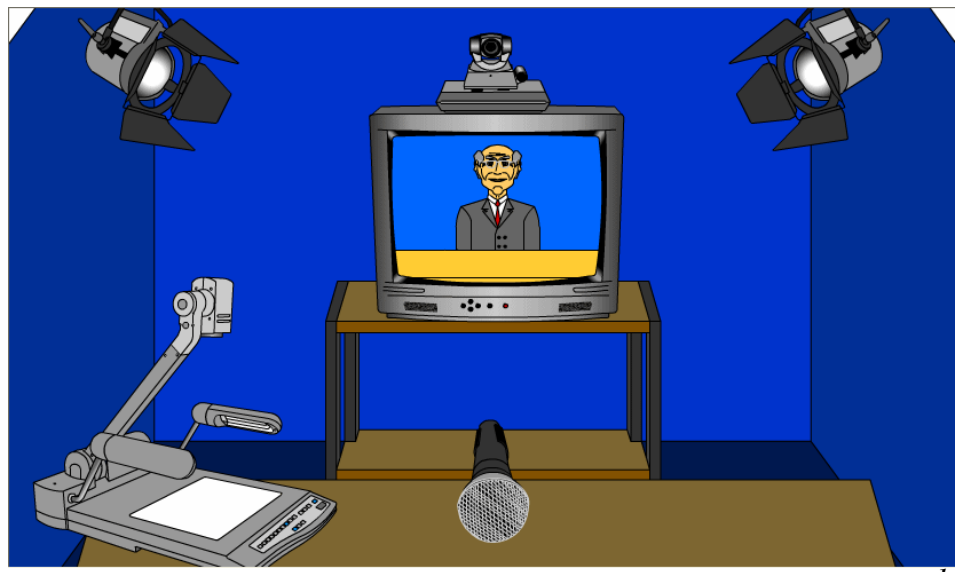

Figura 4 - Primeira versão da animação da sala de videoconferência ${ }^{I}$

A animação da imagem permitirá que o usuário, ao clicar em algum objeto daquela sala, assista ao vídeo com o esquete sobre um problema específico relacionado ao objeto. Então, se ele clicar no microfone, assistirá aos esquetes referentes aos problemas com o som e as dicas e orientações sobre como solucioná-los ou evitá-los. Esta etapa do projeto ainda está em desenvolvimento.

\section{CONTINUANDO A IMPLEMENTAÇÃO}

A análise da imagem da "sala de videoconferência" indicou a necessidade de reformulação de alguns aspectos, como o dimensionamento dos equipamentos desenhados e sua proporcionalidade, a possibilidade de espaço para inclusão de outros recursos tecnológicos e a necessidade de orientações à navegação.

Além disso, pretende-se incluir recursos de interação, prevendo um guia de navegação, proposição de desafios ao navegador e, se necessário, recursos para avaliação dos conhecimentos.

\footnotetext{
${ }^{1}$ Imagem criada pelo bolsista Guilherme Nogueira, que participou da equipe de março a julho, 2007
} 


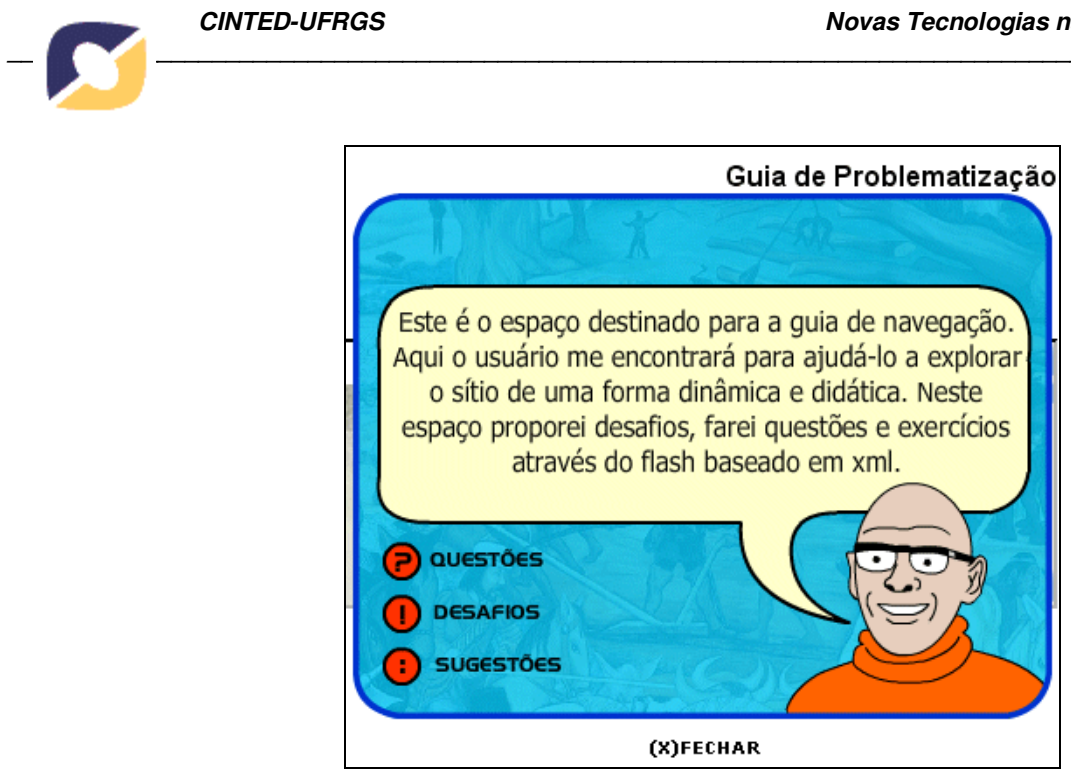

Figura 5 - Modelo de guia de navegação

Como modelo, adotaremos a proposta já disponível para outro espaço no sítio $e$ Psico, implementada em flash baseado em $x \mathrm{ml}^{2}$, como mostra a Figura 5. Esse recurso permite a criação de um banco de dados de questões, que vão sendo apresentadas ao usuário na medida em que navega nos espaços do sítio.

O projeto está em fase final de implementação, quando estão sendo editados os vídeos já gravados para compor o sítio correspondente. Após essa implementação, está prevista uma etapa de testes com alguns usuários para validação do objeto de aprendizagem e sua futura divulgação para os professores da universidade.

Uma proposta a ser estudada é a possibilidade de realização de uma pesquisa junto aos usuários de sistemas de videoconferência, buscando identificar suas dificuldades mais comuns, de forma a trazer maiores subsídios para a continuidade do projeto.

Sobre o terceiro objeto de aprendizagem, que propõe apresentar dicas para a criação de slides a serem incluídos em reuniões via videoconferência, estão sendo adaptadas as orientações propostas por Cattani (2005) ao formato hipertextual do site ePsico.

\section{REFERÊNCIAS BIBLIOGRÁFICAS}

CARNEIRO, M. L.F. O acoplamento tecnológico e a comunicação em rede: inventando outros domínios de aprendizagem. 2003. Tese (Pós-Graduação em Informática na Educação) - Universidade Federal do Rio Grande do Sul, Porto Alegre, 2003.

CATTANI, A.. Elaboração de pôster. 1 $1^{\text {a }}$ ed. Porto Alegre: Editora da UFRGS/PROPESQ, 2005. 56 p.

COSTA, Antonio. Compreender o Cinema. 2a edição, São Paulo, Globo, 1989.

CRUZ, D. e BARCIA, R. Docência a distância em ambientes midiatizados. In: Anais do XXI Encontro Nacional de Engenharia de Produção - ENEGEP 2001, Salvador: ABEPRO, 2001.

\footnotetext{
${ }^{2}$ Extensible Markup Language (XML)é um formato indicado pelo World Wide Web Consortium (W3) para gerar linguagens de marcação e permitir o compartilhamento de informações através da Internet.
} 
CRUZ, D. Linguagem audiovisual e aprendizagem na educação a distância por videoconferência. In: XXII Congresso Brasileiro de Ciências da Computação. Rio de Janeiro, 1999b. Anais. Rio de Janeiro, INTERCOM, 1999. Disponível em: <http://www.intercom.org.br/papers/1999/gt13/13c03.pdf>. Acesso em 20.07.02

CRUZ, D.M. Aprender e ensinar através de videoconferência: percepções e estratégias de alunos e professores num ambiente tecnológico interativo. Tecnologia Educacional, v.29 (145), 1999a.

FIELD, S. Manual do Roteiro: Os fundamentos do texto cinematográfico. Rio de Janeiro: Editora Objetiva, 2001.

HOUAISS, A. e VILLAR, M. Minidicionário Houaiss da Língua Portuguesa. Rio de Janeiro, Objetiva, 2001.

MONTES, J.L.I. e MOLINA, F.D.O. Consideraciones para la implantación de la videoconferencia en el aula. Pixel-Bit Revista de Medios y Educación. Universidad de Sevillha, Espanha. n.17, jun, 2001. Disponível na Internet: http://www.sav.us.es/pixelbit/articulos/n17/n17art/art173.htm. Acesso em 27/10/07.

SABOYA, J. Manual do Autor Roteirista: Técnicas de roteirização para a tv. Rio de Janeiro: Editora Record, 1992.

TAROUCO, L.M.; GRANVILLE, L.; FABRE, M.C. e TAMUSIUNAS, F. Videoconferência - documento de referência. Rede Nacional de Pesquisa (RNP). Grupo de Trabalho Aplicações Educacionais em Rede. março, 2003. Disponível na Internet: http://penta3.ufrgs.br/RNP/videoconferencia.htm. Acesso em 26/10/07.

TEXAS STATE LIBRARY AND ARCHIVES COMISSION. Videoconferencing tips. Disponível na Internet: http://www.tsl.state.tx.us/distancelearning/videoconferencing/tips.html. Acesso em 26/04/07.

UNIVERSITY OF BRITISH COLUMBIA. Guidelines to Lecture Success. Disponível na Internet:

http://www.med.ubc.ca/education/tel/Videoconference_Tips_and_Training/Guidelines_ to_Lecture_Success.htm. Acesso em 26/1/0/07.

UNIVERSITY OF GUELPH. Videoconferencing Tips for Success. Disponível na Internet: http://www.tss.uoguelph.ca/cts/vidcontip.html. Acesso em 26/1/0/07.

WATTS, H. Direção de Câmera: um manual de técnicas de vídeo e cinema. São Paulo: Editora Simmus, 1999. 